\title{
Realtime Control and Monitoring Aquaponic System via Blynk
}

\author{
Wan Ahmad Firdaus Wan Azhar, Mahanijah Md Kamal, Zuhani Ismail Khan and Kama Azura \\ Othman
}

\begin{abstract}
This work helps to control and monitor the aquaponic system in real-time. Aquaponic is a combination of hydroponic and aquaculture where in this work it is the integration of basil and Puyu fish. Normally, the activities such as checking the temperature, humidity and $\mathrm{pH}$ level of the aquaponic system is done manually. Therefore, the aims of this work is to develop a real-time control and monitoring system that can operates wireless via Blynk application. This aquaponic system consists of Puyu Fish or known as anabas testudineus with the hydroponic basil plant based on the seeds and stem cutting techniques. This hardware was built based on Arduino mega as controller, DHT11 sensor, and esp8266 wifi module. The blynk application through a smart phone is used to display the temperature and humidity of the aquaponics system. If the high temperature higher than the setting value of $30^{\circ} \mathrm{C}$, it will quickly notify the user to take appropriate action. From the result obtained it shows that the $\mathrm{pH}$ level of basil is between $6.48-6.68$ using seed technique and $6.71-6.88$ through stem cutting.
\end{abstract}

Index Terms - hydroponic; aquaponic; anabas testudineus; real-time system; temperature; $\mathrm{pH}$ level; blynk application

\section{INTRODUCTION}

Aquaponics combine the hydroponic production of plants and the aquaculture production of fish into sustainable agriculture system that uses natural biological cycles to supply nitrogen and minimizes the use of nonrenewable resources, thus providing economic benefits that can increase over time [1]. Aquaponics farming is an incredibly prolific way to grow organic vegetables, greens, herbs and fruits without using any agro chemicals with the added benefit of fresh fish as a safe, healthy source of protein. It is a revolutionary technique for growing plants, where the aquaculture effluent is diverted through plant beds in a sustainable closed system. Water is the vital for an aquaponic fish receive their oxygen. It is very significant to understand basic water chemistry properly manage aquaponics. The plants, fish, and bacteria in Aquaponics systems entail adequate levels of water temperature, $\mathrm{pH}$, and dissolved oxygen for maximum growth and health [2]. Aquaponics is primarily about of three groups of organisms: fish, bacteria and plants. Each organism in an tolerance range for each parameter of water quality. The ideal temperature is between $18^{\circ} \mathrm{C}$ to $30^{\circ} \mathrm{C}$ while the ph ranging from 6 to 7 for aquaponics parameters [3]. The fish and plants are reliant on the balance of dissolved nutrients and quality of the water, as they generate and utilize metabolic products from each other. Because of the symbiotic uptake and release of nutrients from fish to plants, periodic monitoring of aquaponics system water is essential [4].

This manuscript is submitted on 12th July 2019 and accepted on 10th March 2020. Wan Ahmad Firdaus Wan Azhar, Mahanijah Md Kamal, Zuhani Ismail Khan and Kama Azura Othman are with the Faculty of Electrical Engineering, Universiti Teknologi MARA, 40450 Shah Alam, Selangor.

(e-mail:mahani724@uitm.edu.my)

1985-5389/C 2021 The Authors. Published by UiTM Press. This is an open access article under the CC BY-NC-ND license (http://creativecommons.org/ licenses/by-nc-nd/4.0/).
Aquaponic systems have been developing and the interest in the field has been increasing, not least due to the pressure to produce more food in a sustainable manner for a rapidly increasing world population [5-6]. In this aquaponic system, Puyu fish or known as anabas testudineus was selected because it can adapt by itself in any water conditions. Basil is a fast growing herb with a high economic value, is widely being produced commercially and suitable for aquaponic systems [7]. Besides, basil is accepted as a medicinal herb with various health benefits, such as reduction of inflammation and swelling, antiaging properties, effective antioxidant activities [8]. The other key chemical difference between aquaponic and hydroponic solutions is $\mathrm{pH}$. A crucial point in aquaponic systems is the $\mathrm{pH}$ stabilization, as it is critical to all living organisms within a cycling system that includes fish, plants and bacteria. The optimal $\mathrm{pH}$ for each living component is different. Most plants need a pH value between 6 and 6.5 in order to enhance the uptake of nutrients [9]. The $\mathrm{pH}$ is a parameter that measures the the acidity or alkalinity of a solution. The value indicates the relationship between the concentration of free ions $\mathrm{H}+$ and $\mathrm{OH}-$ in a solution and ranges between 0 and 14. The temperature of the nutrient solution influences the uptake water and nutrients diffirentially by the crop [10]. An important feature of the nutrient solutions is that they must contain the ions in the solution and in chemical forms that can be absorbed by plants closely related with to nutrient uptake and $\mathrm{pH}$ regulation [11]. By controlling the feeding schedule to the fish in the system can overcome problems relating overfeeding that can cause health problems due to high ammonia and nitries, low oxygen levels, low PH levels, and improper digestion of the fish [12]. The implemetation of internet of things (ioT) for aquaponics system were studied actively by these researchers [13-17] to monitor the information remotely via mobile application. Therefore the aims of this work is to design and develop an aquaponic system integrate with basil and Puyu fish which able to control the operation system remotely.

\section{Methodology}

In this work the proposed aquaponic system can be divided into software and hardware part.

\section{A. Block Diagram}

Figure 1 shows the block diagram of the overall system proposed. First, The arduino mega as the brain of the system is attached with the ultrasonic sensor, DHT11 temperature and humidity as well as the water proof temperature sensor. Ultrasonic sensor function as the input condition " 1 " and " 0 " for the water pump to operate. The water proof temperature sensor, DS18B20 will measure the temperature inside the water area. Then the data will be send to the Blynk application via 
ESP8266 Wifi Module through wireless communication. In this Blynk application, it will visualized the temperature inside, and outside the plant area in real time. The primary, and secondary water pump, grow light, and servo motor are triggered with the RTC DS1307 through the timer desired by the user.

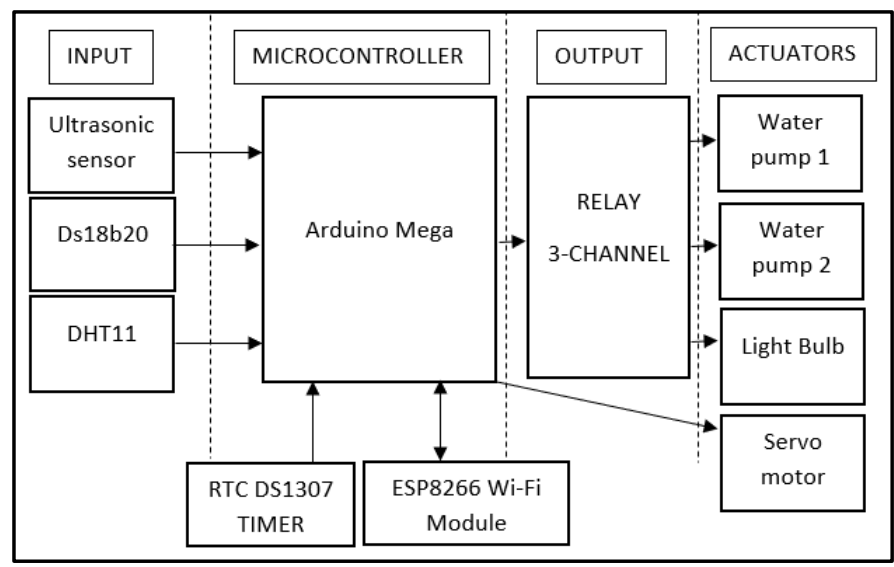

Fig. 1: Block diagram of the system

The arduino microcontroller is used to control the whole operation system. The arduino is chosen because it can operates with the low-voltage supply 7-12 $\mathrm{V}$ and even used a simple $\mathrm{C}++$ programming. The set point is the desired value set up by the user as in Figure 2. The set point will be the desired water level, fish feeder and the monitored temperature at the plants area. The value for the desired water level will be set up with the Ultrasonic sensor as within 0.15 metre range, fish feeder is controlled with the timer and the temperature set point is within $28^{\circ} \mathrm{C}$ until $30^{\circ} \mathrm{C}$ and using the DHT- 11 as the measurement. Then the Arduino received the information from the sensor and comes up with the response as the feedback action, the action will be based on the actuator and works toward to get a desired measurement. The setting elements used in the ckosed-loop system can be reffered in Table I.

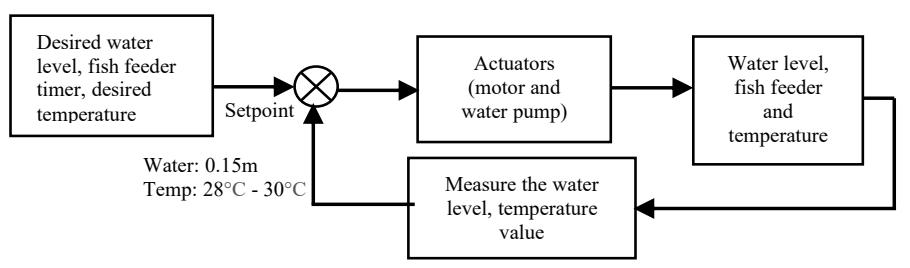

Fig. 2:The closed-loop control

TABLE I

ELEMENTS SETTING

\begin{tabular}{cl}
\hline \hline Elements & \multicolumn{1}{c}{ Components } \\
\hline Setpoint & $\begin{array}{l}\text { Water level: } 0.15 \mathrm{~m} \\
\text { Temperature: } 28^{\circ} \mathrm{C} \text { until } 30^{\circ} \mathrm{C}\end{array}$ \\
Controller & Arduino Mega Board \\
Process/Plant & $\begin{array}{l}\text { Filling the water inside fish tank, } \\
\text { feed the fish and on the grow light }\end{array}$ \\
Actuator & Water pump 1 and 2, Bulb, Motor \\
Feedback & $\begin{array}{l}\text { Ultrasonic sensor, DS18B20 and } \\
\text { Deasurement }\end{array}$ \\
\hline \hline
\end{tabular}

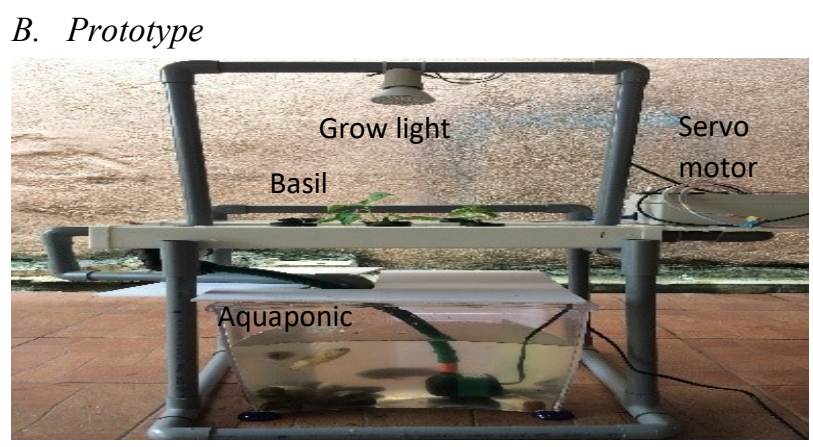

Fig. 3: Prototype setup

Figure 3 shows the experimental setup The design concept came up to build with the balance structure that able to hold the hydroponic tray and the flow of water able to be running smoothly without any water leakage spotted it used Arduino Mega Board as the microcontroller. HC-SR04, DHT11, and Ds $18 \mathrm{~b} 20$ have been used as the input. Meanwhile the actuators side consisted of two water pumps, grow light, and servo motor. A living mechanism used is Puyu Fish and put in an acrylic aquarium with the length of $32 \mathrm{~cm}$, height $31 \mathrm{~cm}$, width $20 \mathrm{~cm}$ in size with a depth of water $20 \mathrm{~cm}$ based on Table 1 . The process is to be observed is the fish excretion of the waste product and to convert the waste into the fertilizer, and the plant absorbs the nutrients through the water containing the fish feces and will oxygenate the water back to the fish. Hydroponic plants such as Basil is used. There are 10 pot holes prepared for the hydroponic plants placement. Table II shows the dimension of the fish tank that covered $32 \mathrm{~cm} \times 21 \mathrm{~cm} \times 20 \mathrm{~cm}$. The material used for it is acrylic. The acrylic material on fish tank is recommended as it is lighter than glass material. Acrylic also stronger than glass material and it can easily be moulded in any different shapes depends on the modification.

TABLE II

\begin{tabular}{cc}
\multicolumn{2}{c}{ THE DESIGN OF FISH TANK } \\
\hline \hline \multirow{2}{*}{ Details } & Aquarium \\
\hline Material & acrylic \\
Length & $32 \mathrm{~cm}$ \\
Height & $31 \mathrm{~cm}$ \\
Wide & $20 \mathrm{~cm}$ \\
\hline \hline
\end{tabular}

\section{Flow Chart}

The flowchart in Figure 4 shows the implementation of the system. at first, the DS1307 will start the timer based on a realtime clock, there will be a 3 initials state of timer initialized within the system as to operate the output parts such as second water pump, grow light, servo motor and buzzer. When the ultrasonic sensor detects the amount of water below the desired water level setpoint, the water pump will on, and the water will flow inside the aquarium. As the ultrasonic sensor depends on the setting up a threshold for the water level inside the fish tank, the sensor will trigger the pumping signal, so the water can flow to the fish tank when it is running low on water and stop the water pump. The other water pump will on when the RTC timer detects every 3 hours gap and the water pump will on once the 
relay is triggered for 15 minutes to make sure the recirculated water inside the fish tank full cover the hydroponic tray.

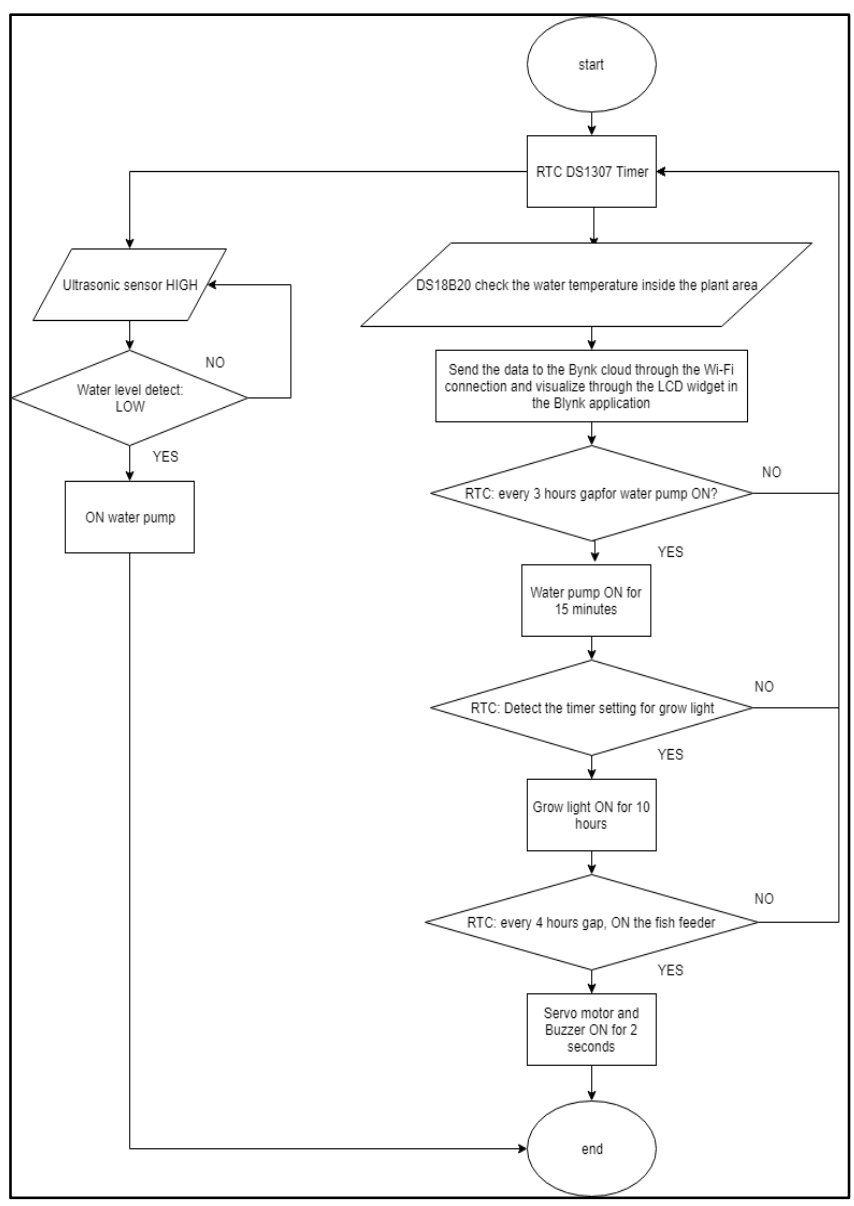

Fig. 4: The Flowchart of the system

The grow light will have the ON and OFF conditions will be depending on a timer. The timer set for the relay attached to the grow light pin to triggered on at 8.15A.M and off at 18.15P.M. The waterproof temperature sensor and Temperature and Humidity sensor also will measure the temperature inside and outside the hydroponic tray and send the data through the Blynk cloud and display the data through the Blynk Apps. The servo motor used as to control food feeder open valve for the fish as it depends on the timer setting inside the microcontroller, the servo motor will on as in actuator will rotate the bottle containing the fish food to pour inside the aquarium.

The aquaculture mechanism used in this work is Puyu Fish (Anabas testudineus) to provide nutrients, and Hydroponic plants, Basil will receive the nutrients from the fish feces. Four fish were used in this project to determine the effectiveness of fish feces. As the water flows, the fish will be feeding with the fish food which can provide all nutrients needed for the plant growth. The scheduling for fish feed was set four times per day and have a 4 hours gap per feeding starts at $8.00 \mathrm{am}$ and ends at $8.00 \mathrm{pm}$. The buzzer sound will on to indicate the scheduling for the fish feeding. The warning notification will up display on the screen smartphone when the high temperature is detected to notify the user to take an action. Table III shown the setup timer as intended to control the actuator.

TABLE III

THE RTC DS1307 SETUP TIMER

\begin{tabular}{cc}
\hline \hline Timer & Output \\
\hline Start the timer from 7:00 a.m. & $\begin{array}{c}\text { Continuously give the input "1" } \\
\text { every } 3 \text { hours to relay pin attach to } \\
\text { the water pump acrylic }\end{array}$ \\
8.15 a.m. and 18:15 p.m. & ON and OFF condition for grow \\
light
\end{tabular}

\section{ESP8266 Wi-Fi Module setup}

Before connecting with the Blynk server and Blynk cloud, a need for initialize the ESP8266 Wi-Fi Module is a must to ensure the smooth wireless connection between the hardware part and the Blynk Application. Compare to the Bluetooth connection, the Wi-Fi connection is more stable and has a wider range connectivity. Hence, a test for ESP8266 must be done to check either the module is in a good condition. At first, ESP8266 had a problem to initialize, after a few troubleshoot and procedure that has been carried out. The problem is solved. The following are the steps to check the Wi-Fi connectivity through the ESP8266.

1. Setup the connection Wi-Fi Modules with the Arduino Mega.

2. Connect the sources of the Wi-Fi Modules with the source of $3.3 \mathrm{~V}$ on the Arduino Mega.

3. Tx Wi-Fi modules connect with the $\mathrm{Tx} 1$ on the Arduino Mega.

4. Rx Wi-Fi modules connect with the Rxl on the Arduino Mega.

5. Upload the sketch of the Wi-Fi module testing on the Arduino Mega to check either the module is working or not.

6. Use Arduino IDE platform to test.

Next, after done checking the ESP8266 Wi-Fi Module functionality. Proceed with the Auth token, SSID, and PASS to connect with the Blynk Server. The Figure 3.9 shows the Wi-Fi connection that has successfully connected to the Blynk Server.

\section{E. Blynk application development}

Blynk is a platform use either android or IOS application to control any development board like Arduino and Raspberry Pi with Internet connection. Blynk is user friendly and can build the digital interface easily. It can control Arduino, Rasberry Pi with the access of WiFi. The Blynk application platform required an account, as to enable the user to have fully control over the application platform. Figures 5, Figure 6 and Figure 7 shows the setting stages to the Blynk application and hence create the user's interface. 


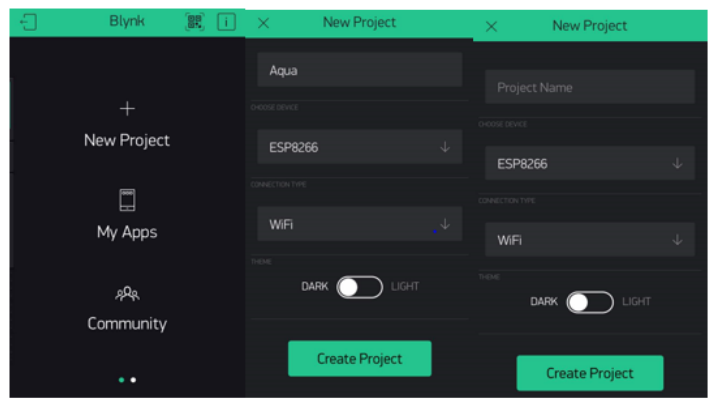

Fig. 5: Initial stage of Blynk platform development

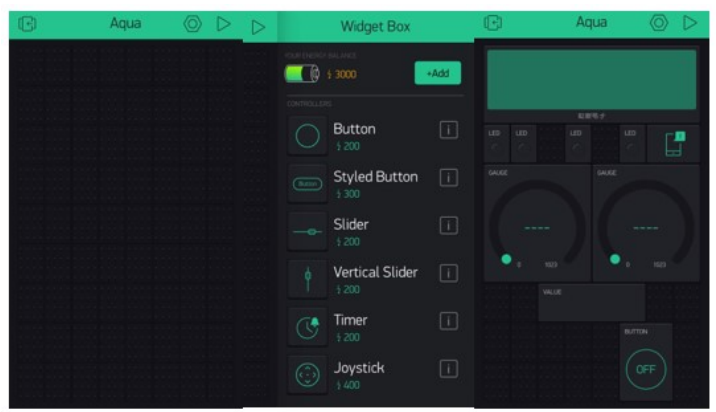

Fig. 6: $2^{\text {nd }}$ stage of Blynk platform development

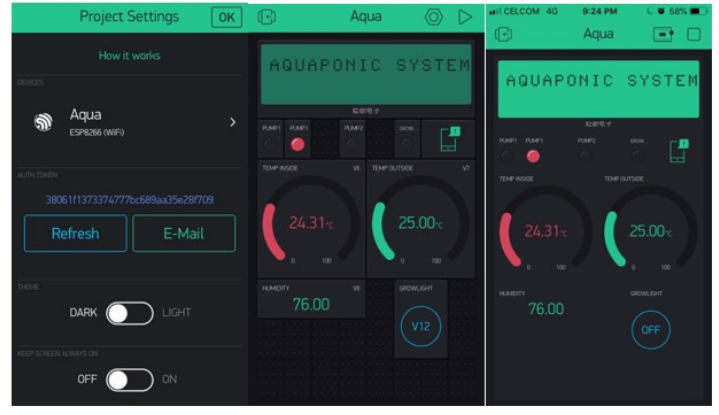

Fig. 7: Final stage of Blynk platform development

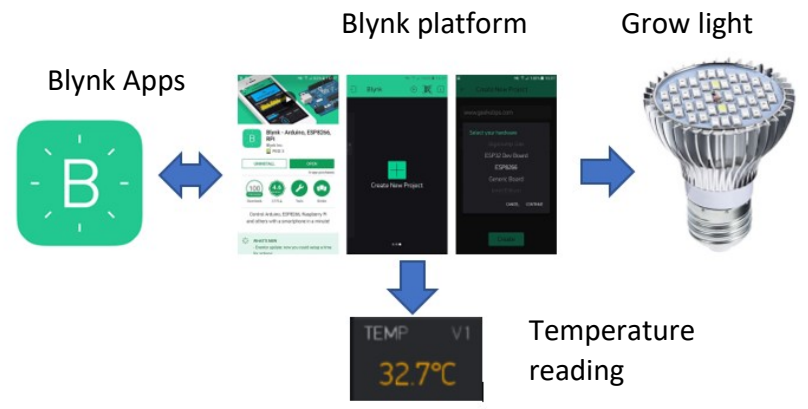

Fig. 8: The process of Blynk

Figure 8 shows the process flow of Blynk application in this work. The inputs data gained through the analog sensors will be converted to digital data inside the Arduino, next those digital data will be sent to the Blynk cloud via Wi-Fi communication. Blynk cloud will interpret the information and lastly send the data to the Blynk apps and able visualize all the sensor data from Ultrasonic sensor, DS18B20, and DHT11 based on real time event. Virtual push button to control the grow light on and off condition also successfully establish.

\section{RESULT AND DISCUSSION}

The arduino mega connected to the Wifi via wireless communication through the ESP8266 Wifi Module and able to communicate. The data obtained from the sensors are displayed through the Blynk application. The temperature inside, temperature outside, and humidity of the hydroponic tray are displayed in real time.

\section{A. Main sensor testing to control water level}

Ultrasonic sensor was placed in a top of fish tank with appropriate distance to avoid from expose to the water, and in a distance that it could attain the input data in term of level distance. The ultrasonic sensor (HC-SR04) is used to control the water pump as to deliver the clean water to the fish tank when the water is below the desirable water level. Sensor needs to be tested to identify the level of accuracy.

The initial water level is set $20 \mathrm{~cm}$ from the ground. If the ultrasonic sensor detects the absence of the water within $15 \mathrm{~cm}$ from the ultrasonic sensor, then it will send the data (1) to the microcontroller, the connected pin to the water pump will ON and the water will fill up the space inside the fish tank until it reaches the desired water level. The Figure 4.1 shows the data that was recorded. The level distance is set at $3 \mathrm{~cm}$ in initial condition.

\section{B. Condition of plant growth relating with temperature}

Water is used as a medium to provides enough nutrient for the plant growths, and oxygen for a good photosynthesis process. With enough nutrient and a good water temperature, the plant can growth healthy.

TABLE IV

WATER TEMPERATURE

\begin{tabular}{cc}
\multicolumn{2}{c}{ WATER TEMPERATURE } \\
\hline \hline Days & Temperature $\left({ }^{\circ} \mathrm{C}\right)$ \\
\hline 1 & 29.30 \\
2 & 28.70 \\
3 & 31.30 \\
4 & 33.08 \\
5 & 32.13 \\
6 & 29.50 \\
7 & 28.70 \\
8 & 28.50 \\
9 & 27.90 \\
10 & 29.60 \\
11 & 28.30 \\
12 & 30.60 \\
13 & 32.50 \\
14 & 31.20 \\
15 & 29.70 \\
16 & 29.56 \\
17 & 30.88 \\
18 & 33.15 \\
19 & 33.24 \\
20 & 29.50 \\
21 & 28.98 \\
22 & 28.16 \\
\hline \hline
\end{tabular}

Table IV shows the temperature of water recorded for 22 days. The data is collected from the waterproof temperature sensor, DS18B20 reading. Figure 9 shows the graph of water temperature data tabulated from the table. During the experiment, the temperature constantly reaches above $30^{\circ} \mathrm{C}$, 
which is not good since the oxygen levels inside the water can be as much as half. This greatly affects the photosynthesis process since the amount of oxygen is decreasing due to the high temperature, and it will affect the plant growth [6]. The temperature inside the water needs to maintain below $30^{\circ} \mathrm{C}$ to keep the oxygen in water nutrition more than half percent desired. If the percentage of oxygen inside the water is drastically dropping, the quality of growth plant process will affect and cause the plan to wilting away.

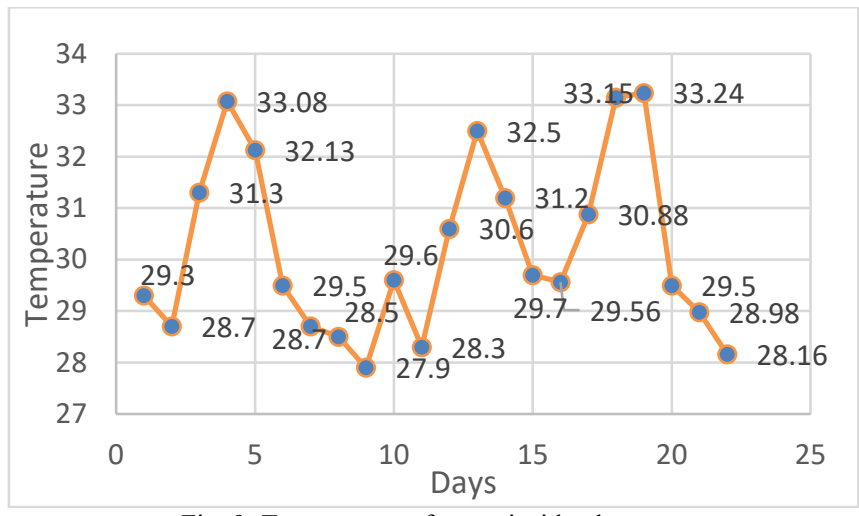

Fig. 9: Temperature of water inside plant area

From the Table V, it showed the germination of seeds started from the $1^{\text {st }}$ day until the 8 th days. The plant through seeds technique is applied to the basil.

TABLE V

THE GROWTH OF BASIL THROUGH SEED TECHNIQUE

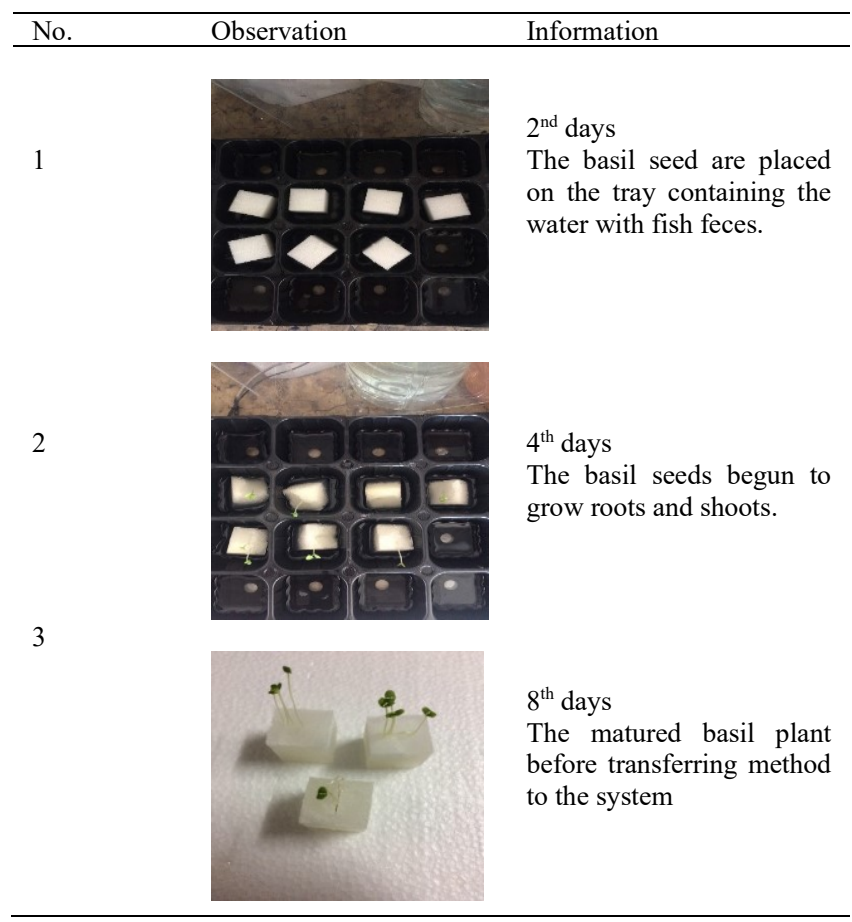

At first these seeds is placed inside the span, and the span put in a tray that filled with the water containing fish feces daily in a confined space based on the non-circulating method.It is in a confined space to ensure the maintained temperature inside the space for a germination phase. This method used to ensure the

plant is in mature phase with a strong stem before transferring them into the aquaponic system. Due to the constant of above $30^{\circ} \mathrm{C}$, the high temperature of the water greatly influences the plant growth. With the low amount of oxygen and the increasing of carbon dioxide in the water, the roots of the plant cannot work efficiently, and it will be leading to the build-up of toxins and with the presence of the toxins the plant unable to take up the nutrient from the water for a healthy plant growth. At the end of Table VI shows the outcome that has ended up with the roots fail to function and leaf damage.

TABLE VI

\begin{tabular}{cl} 
THE GROWTH OF BASIL THROUGH STEM CUTTING TECHNIQUE \\
\hline Observation & Information \\
& $2^{\text {nd }}$ days
\end{tabular}

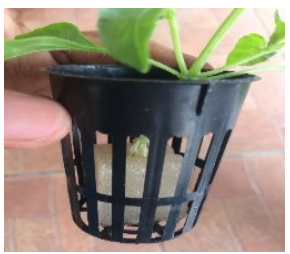

The basil stem is showed a sign of the roots propagated.

2

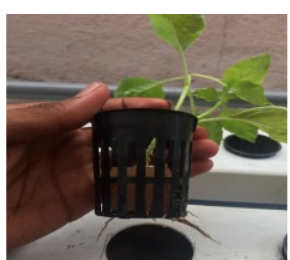

3

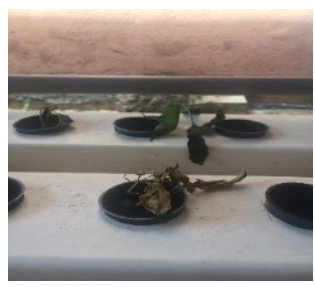

$17^{\text {th }}$ days

The basil stem roots became vigorously spread through the span, and this showed the basil stem is in a good condition. There was no sign of wilt and leaf damage.

22th days

The basil stem begun to be wilting and damage due to uncontrollable temperature of the surrounding.

\section{Conditions of water, basil plant on plant through seeds and stem techniques}

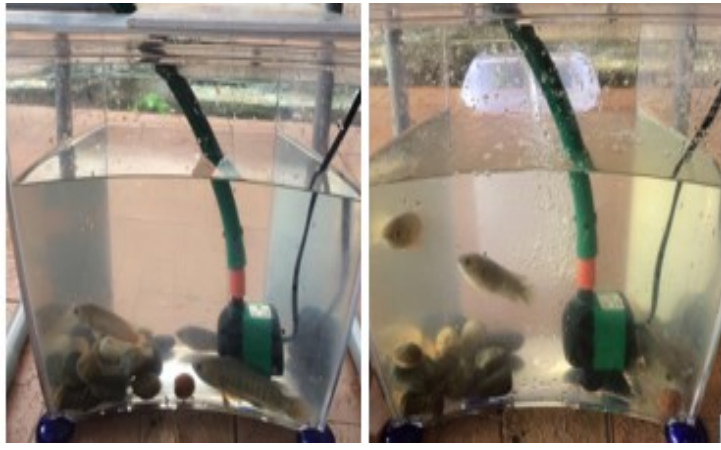

Fig. 10: Water conditions before and after

Figure 10 shown the conditions of water before and after. The initial condition was when the clean water filled inside the fish tank. Meanwhile the final condition was when the water 
exposed with the fish feces by the $3^{\text {rd }}$ day. Initial PH was recorded 6.48 .

TABLE VII

BASIL GROWTH THROUGH SEEDS

\begin{tabular}{ccc}
\hline \hline \multirow{2}{*}{ Days } & Water pH level inside & Height of basil growth $(\mathrm{cm})$ \\
\hline 1 & 6.48 & 0 \\
2 & 6.50 & 0.2 \\
3 & 6.54 & 1.1 \\
4 & 6.58 & 2.0 \\
5 & 6.58 & 2.5 \\
6 & 6.46 & 2.9 \\
7 & 6.55 & 3.5 \\
8 & 6.62 & 3.7 \\
9 & 6.57 & 4.1 \\
10 & 6.52 & 4.1 \\
11 & 6.68 & 4.1 \\
12 & 6.52 & 0 \\
13 & 6.56 & 0 \\
14 & 6.64 & 0 \\
\hline \hline
\end{tabular}

Table VII shown the recorded data the plant through seeds for 2 week. The plant through seeds start at 8 April 2018 to determined the plant growth of Basil. On first day, the seeds was immersed in water. Each day the tray was filled with the water contain of fish feces. On 6 days gap, the clean water was filled to ensure the recirculated of the water.The plant through seeds technique is applied to the basil. At first these seeds is placed inside the span, and the span put in a tray that filled with the water containing fish feces daily in a confined space based on the non-circulating method. The $\mathrm{pH}$ level is measured with the $\mathrm{pH}$ meter daily. The seeds are placed for 1-2 weeks to ensure the plant is mature before transfer them to the aquaponic system, based on the studies basil plant take at least 8 days to become mature and have a strong stem.

TABLE VIII

\section{RECIRCULATION WATER WITH FISH FECES}

\begin{tabular}{ccc}
\hline \hline Day & pH water level with fish & Basil stem \\
\hline 1 & 6.73 & 6.7 \\
2 & 6.81 & 6.7 \\
3 & 6.76 & 6.7 \\
4 & 6.88 & 6.7 \\
5 & 6.84 & 6.8 \\
6 & 6.71 & 6.8 \\
7 & 6.79 & 6.9 \\
\hline \hline
\end{tabular}

Based on Table VIII, it shows the condition of the one of each sample placed in the system within a week. The basil stem is in a good condition, and the roots begin to propagated by day 2 . The pre-mature basil that was placed in the system also in a good condition and slightly burned due to the surrounding temperature, after a few days the plants begun to wilt this was due to the surrounding temperature constantly $29^{\circ} \mathrm{C}-30^{\circ} \mathrm{C}$. For the stem cutting techniques, Figure 11 shown the correlation of $\mathrm{pH}$ water and tempeture realting to the basil growth.

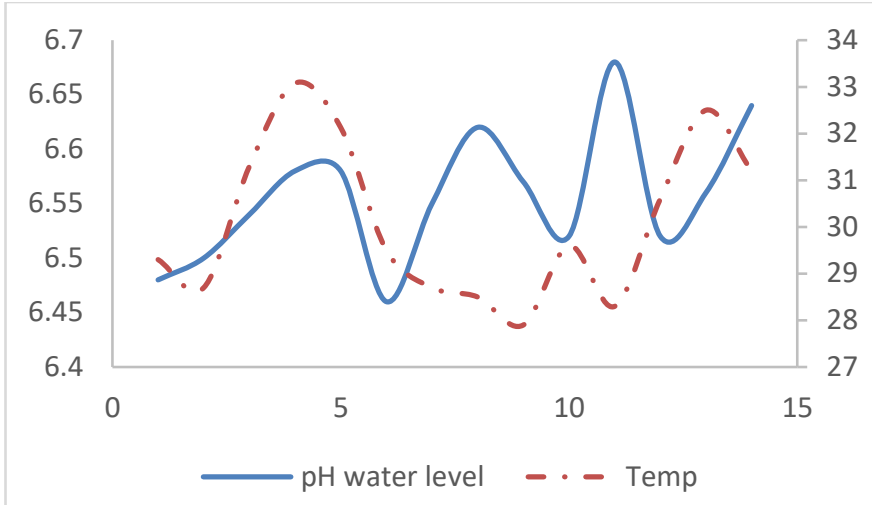

Fig. 11: The correlation between $\mathrm{pH}$ and temperature

\section{Blynk user's interface}

By refering to the internet of thing (IoT) application, the system applies the ESP8266 Wi-Fi module as the link on a prototype system to transmit data and receive data from smartphone application. The smartphone application that used in the system is a Blynk application. Wireless connection with the Blynk Server and Blynk Cloud through the ESP8266 Wi-Fi Module have been successfully established. By then the widget inside the Blynk user interface can be working based on the designated GPIO that has been setup inside the widget settings to visualize the data from the sensors.

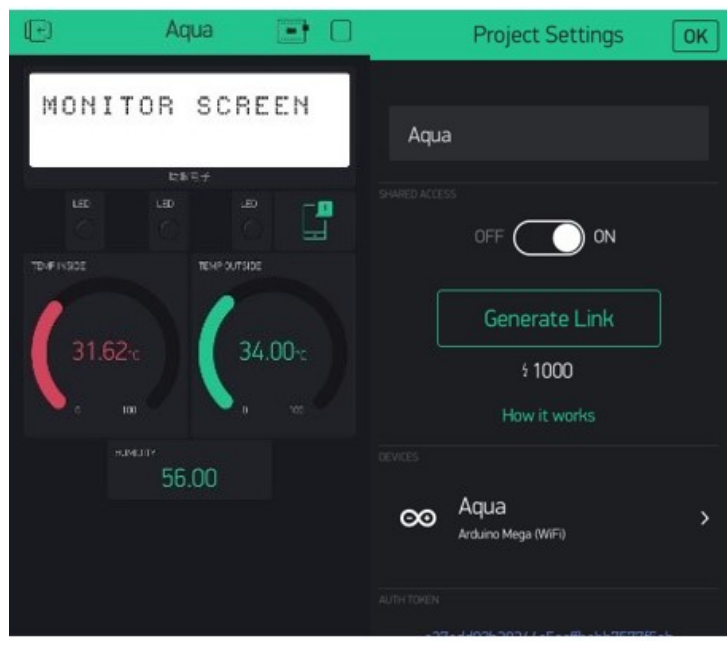

Fig. 12: Blynk user's interface

Figure 12 shows the Blynk user interface is developed using the Blynk platform, as it is easy to build through its platform and very user-friendly. This section shows the screen in the Blynk application when the Arduino Mega is successfully connected to the Blynk Cloud through the Wi-Fi wireless communication. The data begin to appear and shown the same value as the inputs data gained from the sensors. 


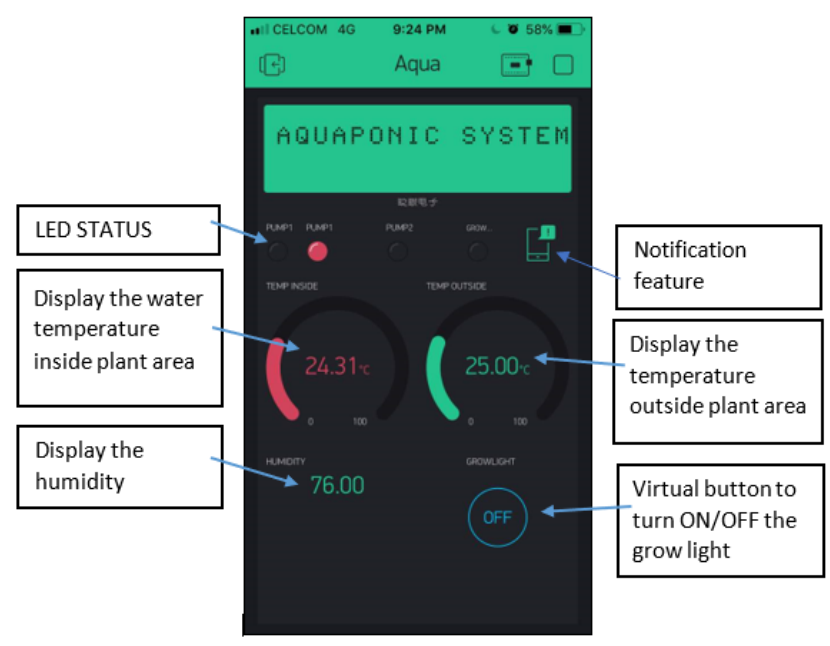

Fig. 13: Blynk application features

Based on Figure 13, it shows the temperature inside, temperature outside, humidity, led status to indicate the status of water pump and grow light, and the virtual button to control grow light on off condition in a Blynk application. The Blynk Cloud will receive the data every 2 seconds loop. If the outside temperature reading is above the desired temperature, the Blynk application will send the notification on the user smartphone as to notify the user to take an initiative regarding the temperature. The user may turn on and off the grow light to lower the temperature of surrounding by using the virtual button in the application or either spray the water around the plant area.

Figure 14 and Figure 15 shows the notifications received through the smartphone to notify the user regarding the high temperature. The Blynk notification is popped up whenever the water temperature is higher than 30 degrees celcius. It is to ensure the user aware of it, and by then take an appropriate action regarding the temperature either to spray the water at the plant area or turn off the grow light by using the virtual button prepared inside the Blynk application.

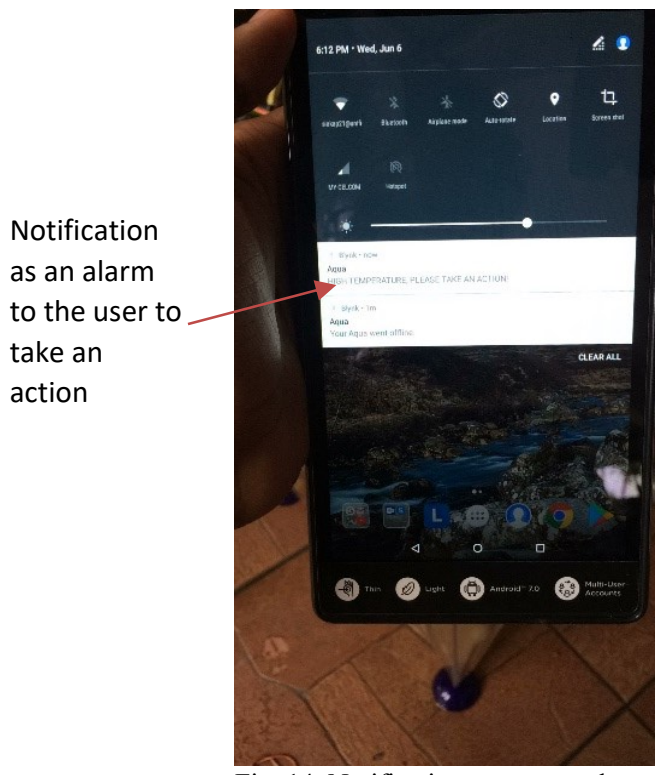

Fig. 14: Notification on a smartphone

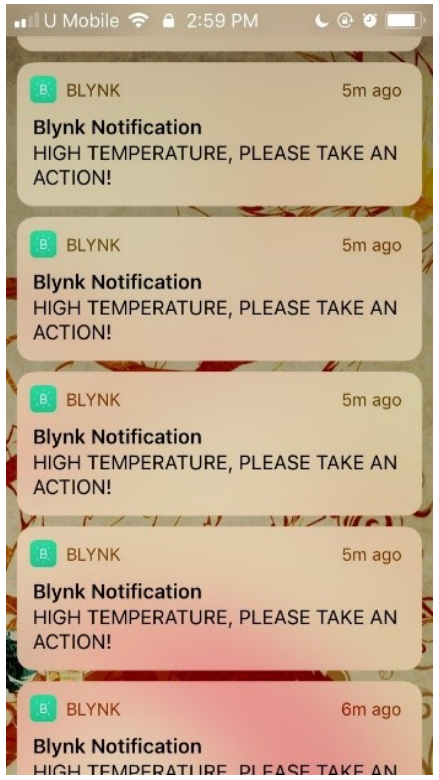

Fig. 15: Notifications through the Blynk Apps when high temperature is detected

\section{CONCLUSION}

The aims of this work is to design a realtime control for aquaponic system with the integration of basil and Puyu fish via Blynk application. From the result obtained, the developed able to monitor the humidity and the temperature of the aquponic system. The growth of basil depends on the nutrients of the water as well as the $\mathrm{pH}$ water. By the application of Blynk it can be concluded that the proposed system able to alert the user and control it remotely.

\section{ACKNOWLEDGMENT}

The authors would like to thank Faculty of Electrical Engineering, Universiti Teknologi MARA, Shah Alam Selangor for their valuable support.

\section{REFERENCES}

[1] R. V. Tyson, D. D. Treadwell, \& E. H. Simonne, "Opportunities and challenges to sustainability in aquaponic systems". HortTechnology, vol. 21 no.1, pp. 6-13. 2011

[2] C Somerville, M Cohen, E Pantanella, A Stankus and A Lovatelli, SmallScale Aquaponic Food Production, Integrated Fish and Plant Farming, FAO, Fisheries and Aquaculture Technical Paper, 2014.

[3] Shafeena, T. "Smart aquaponics system: Challenges and opportunities." European Journal of Advances in Engineering and Technology 3, no. 2 (2016): 52-55

[4] Reshmi Menon and Shahana G.V and Sruthi V, Small Scale Aquaponics System, International Journal of Agriculture and Food Science Technology, 2013, 4 (10), 970-980.

[5] Goddek, S., Delaide, B., Mankasingh, U., Ragnarsdottir, K. V., Jijakli, H., \& Thorarinsdottir, R. (2015). Challenges of sustainable and commercial aquaponics. Sustainability, 7(4), 4199-4224.

[6] Mageau, M., Radtke, B., Fazendin, J. and Ledin, T. (2015). The aquaponics solution. Solutions, 6(3):49-57.

[7] J.E. Rakocy,. Integration of vegetable hydroponics with fish culture: a review. Techniques for modern aquaculture, pp.112-136. 1993.

[8] Selek, M., Endo, M., Yiğit, M. and Takeuchi, T., 2015. The integration of fish and plant production: Nile tilapia (Oreochromis niloticus) and basil (Ocimum basilicum) culture in recirculating and aquaponic systems. Journal of Aquaculture Engineering and Fisheries Research, 3(1), pp.28-43. 
[9] S. Goddek, B. Delaide, U. Mankasingh, K. Ragnarsdottir, H. Jijakli, and R. Thorarinsdottir. Challenges of sustainable and commercial aquaponics. Sustainability, 7(4), pp.4199-4224.2015.

[10] Trejo-Téllez, L.I. and Gómez-Merino, F.C., 2012. Nutrient solutions for hydroponic systems. Hydroponics-a standard methodology for plant biological researches, pp.1-22.

[11] Tyson, Richard V., Danielle D. Treadwell, and Eric H. Simonne. "Opportunities and challenges to sustainability in aquaponic systems." HortTechnology 21, no. 1 (2011): 6-13

[12] M.F.Saaid, A. Sanuddin, M. Ali, and M.S.A.I.M Yassin. Automated pH controller system for hydroponic cultivation. In 2015 IEEE Symposium on Computer Applications \& Industrial Electronics (ISCAIE) (pp. 186-190). IEEE.

[13] M. Manju, V. Karthik, S. Hariharan, and B. Sreekar. "Real time monitoring of the environment parameters of an aquaponic system based on Internet of Things", 2017 Third International Conference on Science Technology Engineering \& Management, pp. 943-947. 2017

[14] Vernandhes, W., Salahuddin, N.S., Kowanda, A. and Sari, S.P., 2017, November. Smart aquaponic with monitoring and control system based on iot. In 2017 Second International Conference on Informatics and Computing (ICIC) (pp. 1-6). IEEE.

[15] A. Dutta, P. Dahal, R. Prajapati, P. Tamang and K.C.E.S. Kumar.'IoT based aquaponics monitoring system", $1^{\text {st }}$. KEC Conference Proceedings, Vol. 1, pp. 75-80. 2018.

[16] R. Vidjya and K. Valarmathi. "Survey on automatic monitoring of hydroponics farms using IoT", Proceedings of the International Conference on Communication and Electronics Systems. Pp. 125-128. 2018.

[17] Haryanto, M. Ulum, A.F. Ibadillah, R. Alfita, K. Aji and R. Rizkyandi. "Smart aquaponic system based Internet of Things (IoT)", IOP Conference Series: Journal of Physics: Conference Series. Pp.1-8. 2019. 